\title{
Penerapan Metode Rank Order Centroid dan Additive Ratio Assessment Pada Aplikasi Rekomendasi Supplier
}

\author{
Ronny Addenan*1, Wilda Susanti ${ }^{2}$ \\ ${ }^{1}$ Program Studi Sistem Informasi, Institut Bisnis dan Teknologi Pelita Indonesia \\ ${ }^{2}$ Program Studi Teknik Informatika, Institut Bisnis dan Teknologi Pelita Indonesia \\ email: ronnyaddenan240@gmail.com**1,wilda@lecturer.pelitaindonesia.ac.id ${ }^{2}$
}

(Received: 14 Maret 2021/ Accepted: 15 April 2021 / Published Online: 20 Juni 2021)

\begin{abstract}
Abstrak
PT.Yanmarindo Perkasa merupakan sebuah perusahaan yang bergerak di bidang penjualan mesin diesel engine, generator, alat perkakas dan spare part mesin. Banyak supplier yang ingin mendistribusikan barangnya melalui PT Yanmarindo Perkasa, sehingga menuntut perusahaan untuk memilih supplier yang tepat, guna menjamin kelancaran pemenuhan stok barang. Proses pemilihan supplier masih dilakukan secara manual dengan kriteria yang terbatas pada kriteria kuantitatif, sehingga proses menjadi lama dan hasil kurang tepat. Tujuan penelitian ini membangun sistem penunjang keputusan untuk rekomendasi supplier secara cepat dan tepat dalam memenuhi kebutuhan perusahaan. Proses pemilihan supplier menggunakan metode Rank Order Centroid (ROC) untuk pembobotan kriteria dan Additive Ratio Assessment (ARAS) untuk perangkingan. Nilai ARAS yang didapat berupa nilai $\mathrm{K}$ yang di ranking untuk mendapatkan supplier terbaik dengan menggunakan sistem pendukung keputusan berbasis komputerisasi. Penerapan kedua metode ini dapat mempercepat hasil keputusan, tidak memakan waktu yang lama dan hasil yang didapat juga maksimal.
\end{abstract}

Kata kunci: Sistem Pendukung Keputusan, Supplier, Rank Order Centroid, Additive Ratio Assessment.

\begin{abstract}
PT.Yanmarindo Perkasa is a company in the sale of diesel engines, generators, tooling tools and engine spare parts. Many suppliers want to distribute their goods through PT.Yanmarindo Perkasa, thus demanding the company to choose the right supplier, in order to ensure the smooth fulfillment of stock items. The process of selecting suppliers is still done manually with criteria limited to quantitative criteria, so that the process takes a long time and the results are not precise. The purpose of this study is to build a decision support system for supplier recommendations quickly and precisely in meeting the company's needs. The supplier selection process uses the Rank-Order Centroid (ROC) method in weighting the criteria and the Additive Ratio Assessment (ARAS) for ranking. ARAS value obtained is the $K$ value that is ranked to get the best supplier by using a computerized decision support system. The application of these two methods can speed up the results of decisions, does not take a long time and the results obtained are also maximum.
\end{abstract}

Keywords: Decision Support System, Supplier, Rank Order Centroid, Additive Ratio Assessment.

\section{PENDAHULUAN}

Perkembangan teknologi yang semakin pesat memberikan dampak dalam kehidupan kita baik positif maupun negatif. Dalam dunia bisnis, kemajuan teknologi yang pesat tersebut menyebabkan proses pengambilan keputusan juga membutuhkan teknologi informasi. Di era globalisasi ini perusahaan dituntut untuk bergerak cepat dalam pengambilan keputusan dan tindakan yang tepat. Pengambilan suatu keputusan merupakan sesuatu yang penting dalam menentukan keputusan yang harus diambil dalam menghadapi persaingan dunia bisnis. 
Pengambilan keputusan dipengaruhi oleh beberapa aspek, hal ini yang dapat mempengaruhi kecepatan pengambilan keputusan yang cepat dan akurat oleh decision maker (Fella, Susant, \& Nora, 2020; Majdi, 2017).

PT.Yanmarindo Perkasa merupakan perusahaan distributor yang berhubungan langsung dengan supplier dan customer yang berorientasi ingin memuaskan customer, dan banyaknya supplier yang ingin mendistribusikan barangnya melalui PT.Yanmarindo Perkasa, maka perusahaan diharuskan untuk memilih supplier yang dapat menjalin kerja sama dengan baik dan menguntungkan guna menjamin kelancaran operasional perusahaan dan pemilihan supplier di PT.Yanmarindo Perkasa ini sangat berpengaruh pada kelancaran pemenuhan stok barang, jika kriteria tidak sesuai maka perusahan tidak dapat memenuhi kebutuhan pelanggan dengan maksimal. Disinilah peran SPK dibutuhkan untuk pengambilan keputusan dalam memilih rekomendasi supplier dan Tujuannya adalah menjadi alat bantu bagi para pengambil keputusan untuk memperluas kapabilitas dengan melakukan pemilihan supplier yang handal sesuai dengan kriteria yang dibutuhkan oleh perusahaan (Wardani, Parlina, \& Revi, 2018).

Proses penentuan supplier saat ini masih kurang efisien, padahal proses pemenuhan kebutuhan ini sering dilakukan. Penentuan supplier selama ini masih dilakukan secara manual dengan mempertimbangkan aspek harga dan penilaian yang bersifat subjektif seperti pelayanan sedangkan dalam sistem yang baru, kriteria-kriteria yang akan dijadikan pertimbangan dalam pemilihan rekomendasi supplier adalah harga, pelayanan (komunikasi \& attitude), limit, termin, kecepatan respon dan garansi. Sistem yang dilakukan secara manual dengan kriteria yang sudah ada sebelumnya tentu tidak dapat memberikan hasil yang akurat dalam menentukan rekomendasi supplier, karena kriteria yang digunakan untuk seleksi supplier hanya harga dan tidak bersifat objektif. Padahal kriteria lain yang non cost sangat mempengaruhi penilaian dan dapat digunakan untuk menilai kinerja supplier.

Pada penelitian sebelumnya dalam sistem keputusan pemilihan supplier yang dilakukan, telah ada yang menggunakan metode MOORA, SAW, WP dan lainnya seperti Pemilihan Supplier Obat yang tepat dengan Metode Simple Additive Weighting (Trimulia, Defit, \& Nurcahyo, 2018). Penentuan Supplier Bahan Baku Restaurant XO Suki Menggunakan Metode Weight Product (Laila \& RMS, 2019) Sistem Pendukung Keputusan Pemilihan Supplier Barang Menerapkan Metode MOORA (Mesran, 2018) dimana metode yang digunakan semua untuk pengambilan keputusan pemilihan suplier berdasarkan bobot nilai dan kriteria. Metode Rank Order Centroid dan Additive Ratio Assessment, dilakukan pada objek yang berbeda seperti pemilihan Jaksa Terbaik (Ndruru, 2020), Pemilihan Kepala Lingkungan (Handayani, Syahrizal, \& Tampubolon, 2019), Penilaian Kinerja Karyawan (Mesran, Afriany, \& Sahir, 2019) dan belum ada untuk rekomendasi supplier. Metode ini melakukan perhitungan bobot menggunakan Rank Order Centroid agar pembobotan terhadap kriteria menjadi lebih baik karena ROC merupakan metode sederhana yang dapat menghasilkan nilai bobot terhadap kriteria yang digunakan (Badaruddin, 2019) menghasilkan kinerja tertinggi dalam dalam hal identifikasi alternatif (Ahn, 2011) serta mengatasi proses pembobotan atribut dalam pengambilan keputusan (Lubis, Sihombing, \& Nababan, 2020) dan Metode Additive Ratio Assessment yang secara garis besar banyak melakukan perangkingan dengan cara membandingkan dengan alternative lainnya sehingga mendapatkan hasil yang ideal dan terbaik (Zavadskas \& Turskis, 2010; Pratiwi et al., 2019; Supriyanto et al., 2019).

Atas dasar permasalahan diatas maka dirancang sistem pendukung keputusan rekomendasi supplier berbasis komputer. Pemilihan supplier perlu dilakukan untuk mendapatkan supplier yang mampu memenuhi kebutuhan perusahaan secara konsisten dan apabila supplier kurang bertanggung jawab dan respons terhadap pemenuhan permintaan maka akan menimbulkan masalah antara lain terjadinya kesalahan fatal di perusahaan dalam pemilihan rekomendasi supplier dalam pemenuhan kebutuhan perusahaan (Mesran, 2018). 
Proses pemilihan supplier dilakukan dengan cara mengevaluasi supplier dan membandingkan dengan menggunakan kriteria dan bobot yang sesuai menggunakan model yang tepat yaitu Rank Order Centroid (ROC) dan Additive Ratio Assessment (ARAS). Sehingga hal ini dapat membantu perusahaan dalam melakukan pemilihan supplier yang tepat untuk memenuhi kebutuhan produk sesuai dengan yang diharapkan.

\section{METODE}

Dalam melakukan penelitian ini, metode yang digunakan adalah metode SDLC, memiliki beberapa tahapan seperti yang terlihat pada gambar 1 .

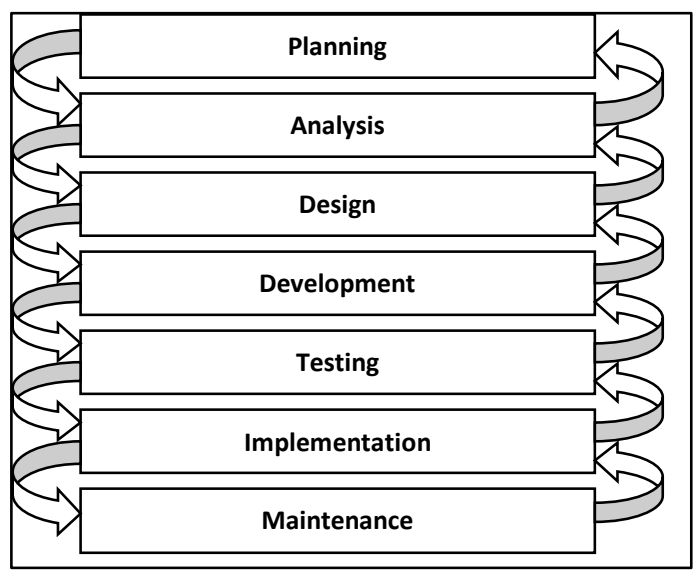

Gambar 1. Metode System Development Life Cycle (SDLC)

Planning, yaitu dengan mengumpulkan data yang ada dan diperlukan dengan melakukan wawancara, observasi, dan menyimpulkan kegiatan-kegiatan yang berlangsung di PT. Yanmarindo Perkasa khususnya dalam pemilihan rekomendasi supplier (Laila \& RMS, 2019). Analysis, Dalam tahapan ini peneliti menganalisis dan menemukan bahwa sistem dalam pemilihan rekomendasi supplier dalam pemenuhan kebutuhan perusahaan masih bersifat konvensional atau manual (Rizki \& Mulyati, 2020; Sakti et al., 2020). Design, Pada tahap ini, pengembang akan mendesain rancangan sistem baru yang berjalan sesuai dengan input, proses, dan output yang akan dihasilkan oleh sistem baru. Rancangan sistem baru pun disesuaikan dengan kebutuhan dan permintaan dari user (Kwok \& Susanti, 2019).

Development, Setelah melakukan perancangan, membuat sistem baru menggunakan pemrograman Delphi 7 dan database MySQL sebagai media penyimpanan database. Untuk membangun sistem penunjang keputusan pemilihan rekomendasi supplier, peneliti menerapkan metode ROC dan ARAS sebagai metode perhitungan dalam pemilihan rekomendasi supplier. Testing, Tahap ini dilakukan pengujian sistem yang telah dibuat, menguji kelayakan sistem untuk diterapkan dalam perusahaan dan apakah ada terjadi error atau hal - hal yang tidak normal yang terjadi pada program tersebut (Muntohar, 2020). Implementation, Tahapan ini program telah selesai dibuat dan diuji coba apakah sudah baik untuk digunakan dan melakukan training user dalam penggunaan sistem. Maintenance, Peneliti akan melakukan pemeliharaan sistem untuk menjaga agar tidak ada bug yang terjadi atau gangguan yang lainnya. Namun pemeliharaan sistem masih bersifat manual dan peneliti diharuskan datang ke perusahaan karena sistem masih bersifat offline menggunakan Pemrograman Delphi 7. 


\section{HASIL DAN PEMBAHASAN \\ Hasil}

Atas berbagai kekuatan yang dimiliki perusahaan yang masih harus ditingkatkan, kelemahan yang harus diperbaiki, kesempatan yang ada dan ancaman yang harus diminimalisir maka diusulkan sebuah SPK rekomendasi supplier pada PT.Yanmarindo Perkasa dengan menerapkan metode ROC dan ARAS. Disamping rancangan SPK penentuan supplier berbasis komputer yang sebelumnya masih dilakukan secara manual dengan menggunakan spread sheet, langkah penting dalam proses perancangan adalah dengan melakukan pemodelan grafik. Penelitian ini menggunakan pemodelan grafik UML untuk membuat model rancangan SI baru. Berikut ini dijabarkan model grafis UML untuk SI baru dimulai dari Usecase Diagram, Activity Diagram, Object Diagram dan Class Diagram.

Usecase Diagram ditetapkan paling awal untuk menjelaskan secara umum interaksi antara lingkungan luar dengan sistem. Artinya, tiap usecase menyatakan kejadian yang dilakukan aktor terhadap sistem di mana aktor utama adalah kepala pembelian dan pimpinan. Gambar 2 menggambarkan rancangan usecase diagram sistem baru di mana kepala pembelian membuka aplikasi dan melakukan login, lalu menetapkan kriteria lalu proses metode ROC dan mengisi penilaian supplier lalu proses metode ARAS dan mendapatkan hasil perangkingan supplier. Setelah itu kepala pembelian akan mencetak laporan, sebelumnya pimpinan akan membuka aplikasi dan login lalu memvalidasi laporan tersebut setelah itu kepala pembelian bisa mencetak laporan pemilihan supplier tersebut.

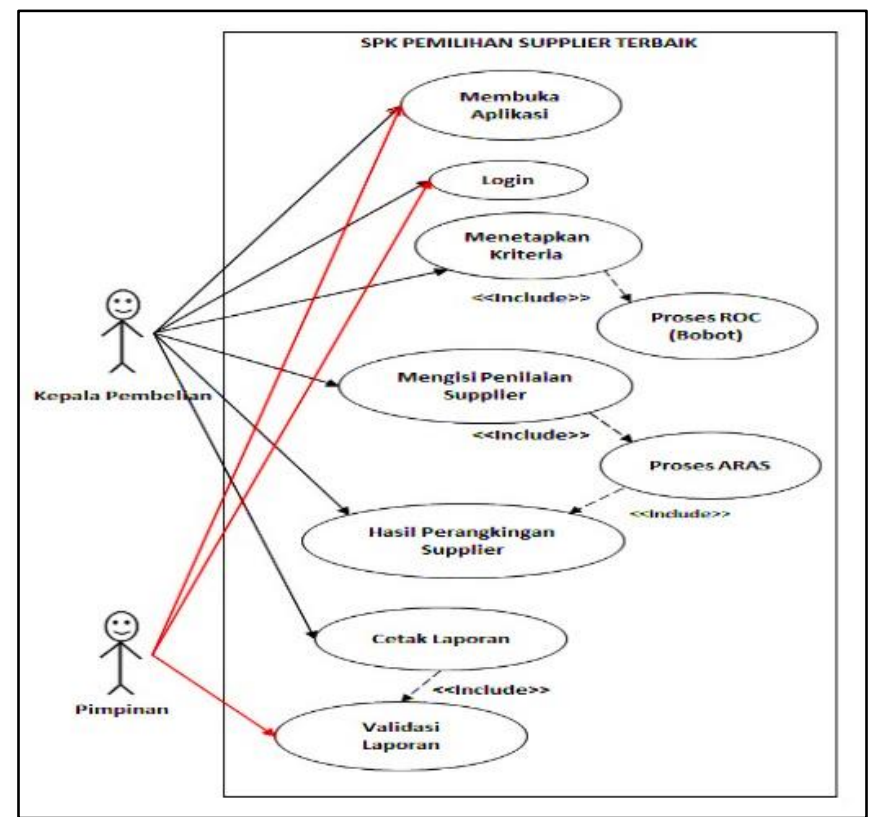

Gambar 2. Usecase Diagram

Aktivitas yang terjadi pada gambar 3 menunjukkan aliran kerja pada sistem perusahaan yang baru. Terlihat ada start state berupa simbol lingkaran kecil berwarna hitam yang menunjukkan awal aktivitas sistem. Aktivitas sistem dimulai dengan membuka aplikasi dan dilanjutkan dengan login ke dalam sistem, setelah itu kepala pembelian menetapkan kriteria dan terjadi proses perhitungan bobot metode ROC. Kemudian kepala pembelian mengisi data penilaian supplier dan terjadi proses perhitungan metode ARAS yang akan menghasilkan supplier terbaik, lalu hasil supplier terbaik tersebut akan di validasi terlebih dahulu oleh pimpinan dan kemudian akan dicetak laporan supplier terbaik oleh kepala pembelian. Activity 
Diagram ini diakhiri dengan end state yaitu berupa simbol lingkaran kecil dengan arsiran berwarna hitam tidak penuh.

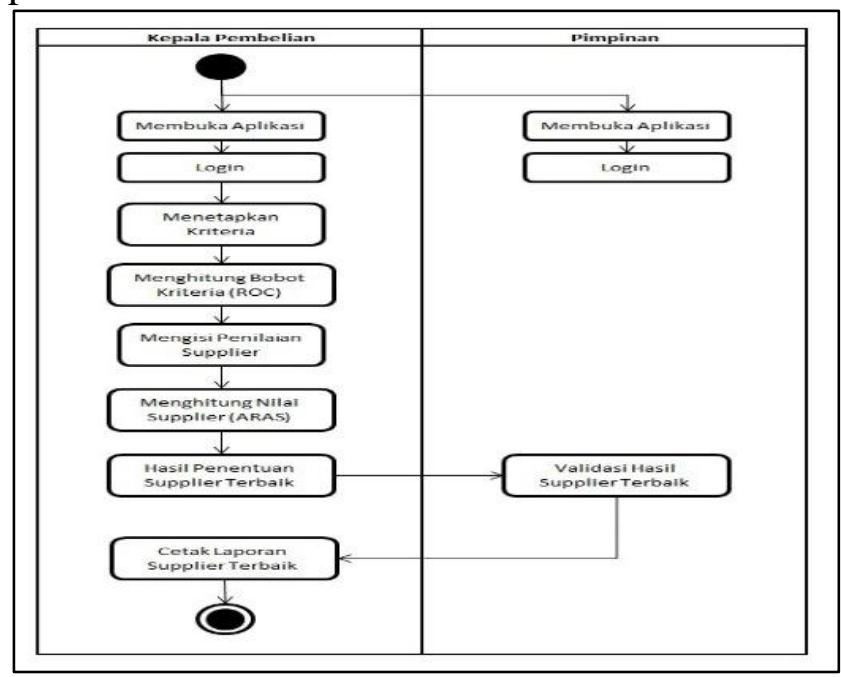

Gambar 3. Activity Diagram

Gambar 4 merupakan Form Login, dimana user melakukan login dengan memasukan username dan password untuk bisa akses kedalam sistem. Selanjutnya, gambar 5 merupakan Form Tampilan Input Data Penilaian Supplier, dimana user menginput tanggal, kategori supplier, nama supplier, dan penilaian. Sementara itu, gambar 6 merupakan Form Perhitungan Penilaian Supplier yang digunakan sebagai perhitungan rekomendasi supplier dan juga hasil perangkingan rekomendasi supplier.

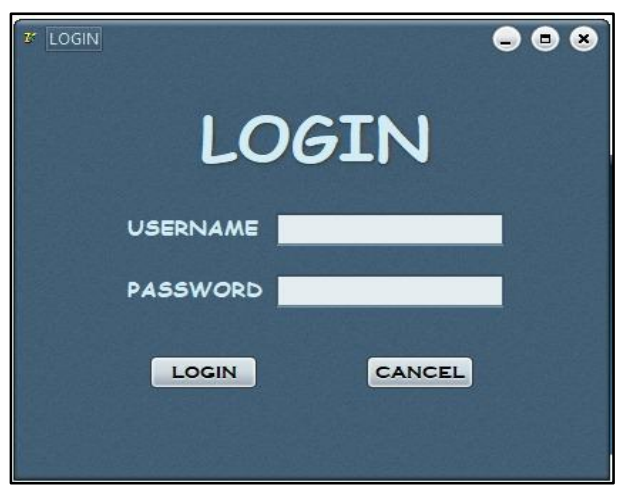

Gambar 4. Form Login

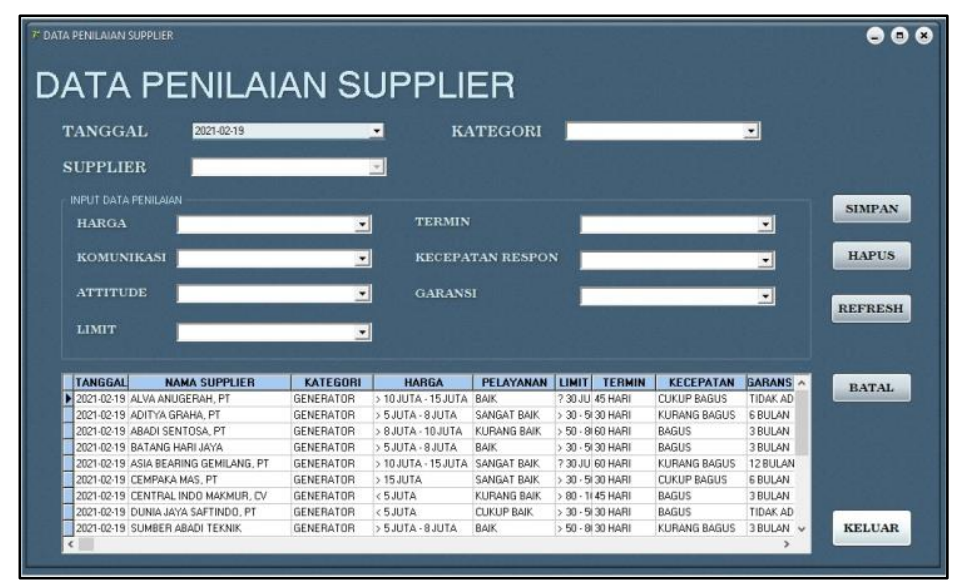

Gambar 5. Form Tampilan Input Data Penilaian Supplier 


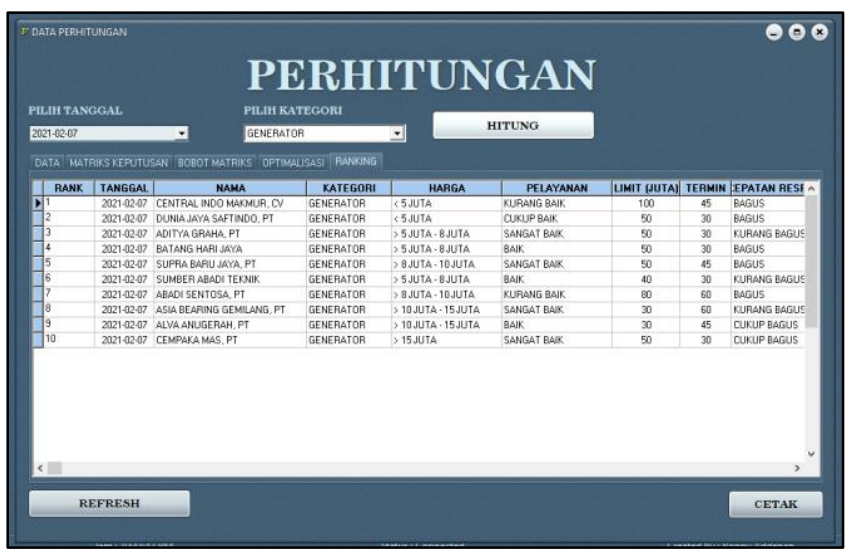

\section{Pembahasan}

Gambar 6. Form Perhitungan Penilaian Supplier

Metode SPK yang digunakan oleh peneliti adalah metode ROC dan ARAS. Metode ARAS ini sangat mudah dan sederhana dalam menghasilkan keputusan. Namun dalam penerapan metode ARAS bobot masih dihasilkan dengan pemberian nilai langsung dalam proses perangkingan. Hal ini tentu memberikan kelemahan besar dalam perangkingan metode ARAS, agar pembobotan terhadap kriteria menjadi lebih baik maka penulis menggunakan metode ROC yang merupakan metode sederhana yang dapat menghasilkan nilai bobot terhadap beberapa kriteria yang digunakan (Ndruru, 2020). Berikut Alur perhitungan beserta hasil perhitungan (lihat gambar 7).

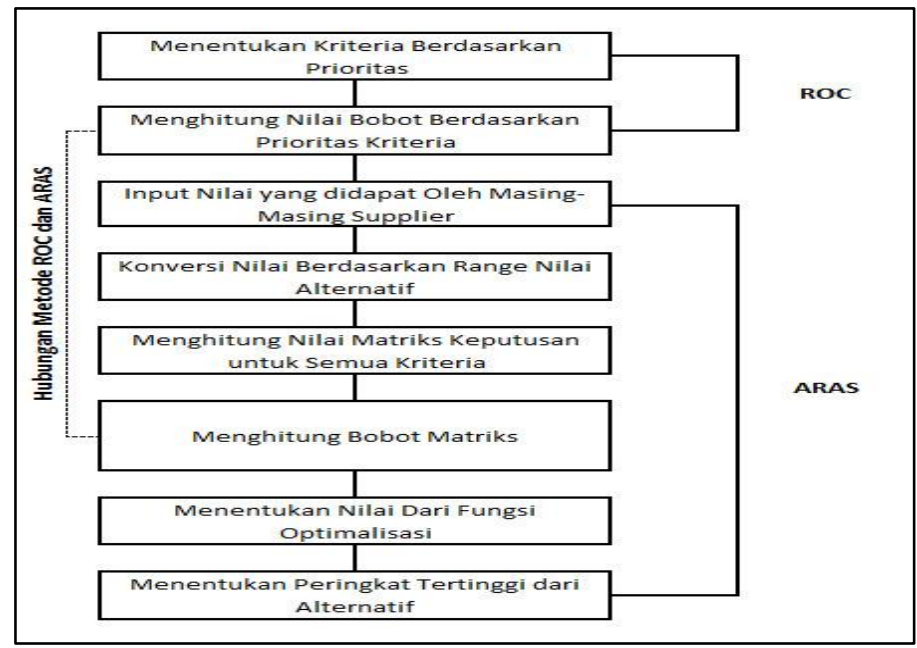

Gambar 7. Alur Perhitungan

\section{Menentukan Kriteria Berdasarkan Prioritas.}

Adapun kriteria dan bobot pemilihan supplier, kriteria yang ada sudah ditentukan berdasarkan prioritas di mana harga lebih penting daripada pelayanan, pelayanan lebih penting daripada limit dan seterusnya (lihat tabel 1).

\section{Data Penilaian Supplier}

Pada tabel 2, tabel data penilaian supplier, yaitu data sampel yang digunakan untuk melakukan penilaian, dan penilaian yang ada meliputi harga, pelayanan yang terbagi menjadi 2 yaitu komunikasi dan attitude, limit, termin, kecepatan respons dan garansi .

\section{Konversi Nilai Berdasarkan Nilai Range}

Pada tabel 3, tabel data penilaian yang telah dinormalisasi berdasarkan range nilai, di mana tiap kriteria telah ditentukan range nilai dari 1 sampai dengan 5. 
Tabel 1. Tabel Data Kriteria \& Hasil Bobot Kriteria

\begin{tabular}{ccccc}
\hline Id_Kriteria & Nama_Kriteria & Sub Kriteria & Jenis & Bobot \\
\hline C1 & Harga & & Benefit & 0.408 \\
C2 & Pelayanan & Komunikasi & Benefit & 0.242 \\
C3 & Limit & & Benefit & 0.158 \\
C4 & Termin & & Benefit & 0.103 \\
C5 & Kecepatan Respons & & Benefit & 0.061 \\
C6 & Garansi & & Benefit & 0.028 \\
\hline
\end{tabular}

\section{Menghitung Nilai Bobot Berdasarkan Prioritas Kriteria}

Adapun penetapan prioritas kriteria dan perhitungan nilai bobot untuk setiap kriteria penilaian supplier dijelaskan sebagai berikut (Handayani et al., 2019):

Jika $\mathrm{Cr}_{1} \geq \mathrm{Cr}_{2} \geq \mathrm{Cr}_{3} \geq \ldots \geq \mathrm{Cr}_{\mathrm{n}}$

Jika k merupakan banyaknya kriteria, maka :

$\mathrm{W} 1=\frac{1+\frac{1}{2}+\frac{1}{3}+\cdots+\frac{1}{\mathrm{k}}}{\mathrm{k} 2=\frac{0+\frac{1}{2}+\frac{1}{3}+\cdots+\frac{1}{\mathrm{k}}}{\mathrm{k}}}$
Maka $\mathrm{W}_{1} \geq \mathrm{W}_{2} \geq \mathrm{W}_{3} \geq \ldots \geq \mathrm{W}_{\mathrm{n}}$.

$$
\begin{aligned}
\mathrm{W} 3 & =\frac{0+0+\frac{1}{3}+\cdots+\frac{1}{\mathrm{k}}}{\mathrm{k}} \\
\mathrm{W} 4 & =\frac{0+\cdots+0+\frac{1}{\mathrm{k}}}{\mathrm{k}}
\end{aligned}
$$

Berikut adalah perhitungan Metode ROC sesuai dengan kriteria pada tabel 1.

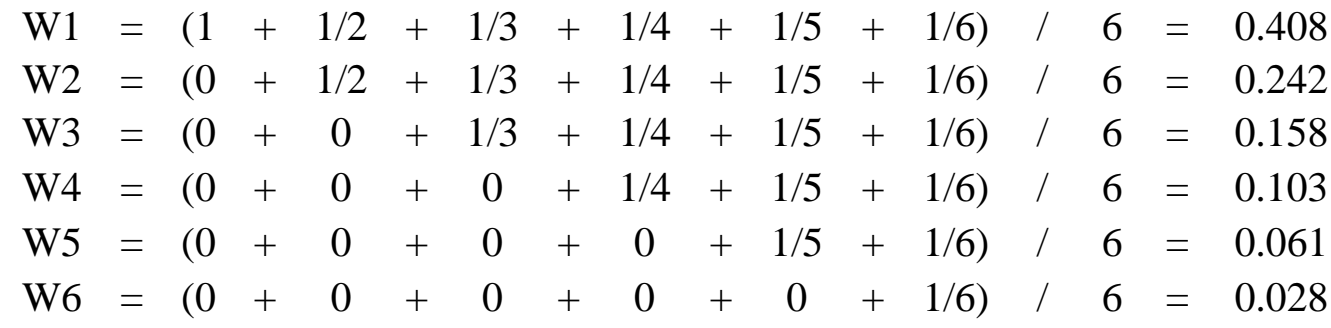

Tabel 2. Tabel Data Penilaian Supplier

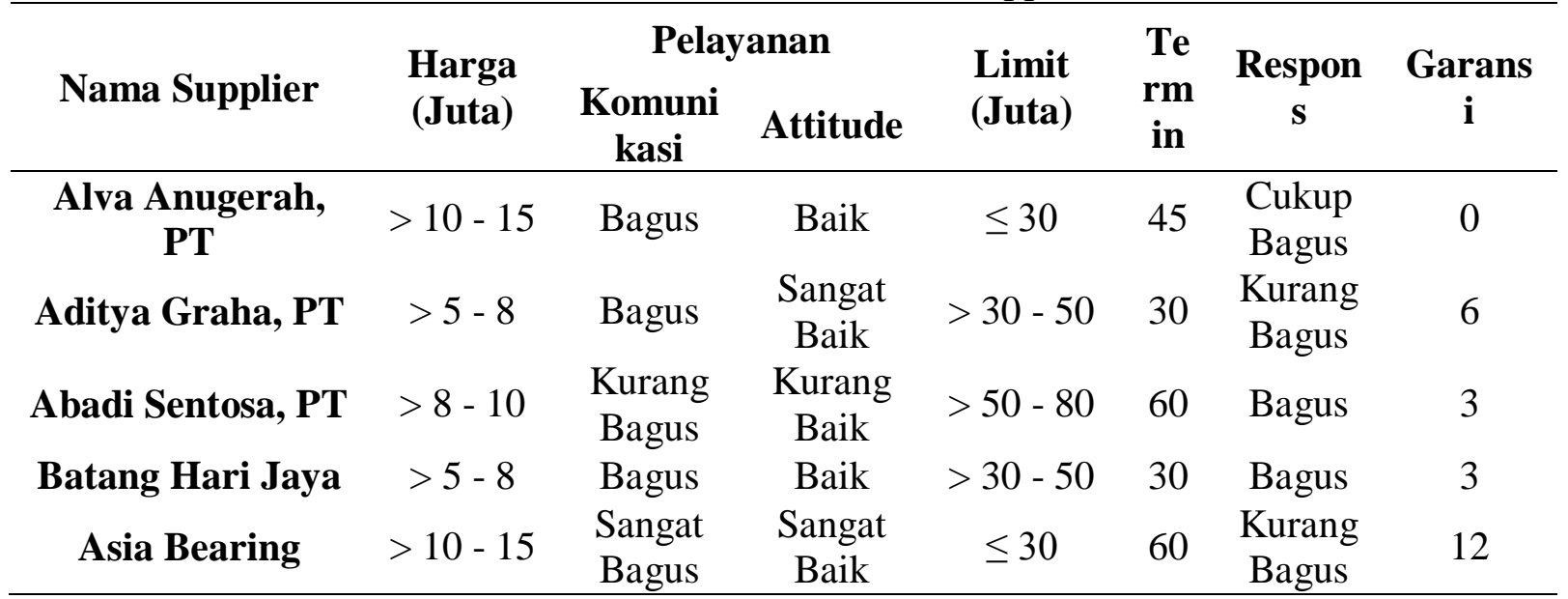

\section{Menghitung Nilai Matriks Keputusan Setiap Kriteria}

Pada tabel 4 adalah data hasil perhitungan matriks keputusan yang didapat dari nilai alternatif setiap kriteria dibagi dengan nilai total setiap kriteria. Total setiap kriteria didapat dari penjumlahan nilai $\max$ dan nilai semua alternatif setiap kriteria. 
Tabel 3.Tabel Data Penilaian Setelah Dinormalisasi

\begin{tabular}{cccccccc}
\hline Id Supplier & Harga & Pelayanan & Limit & Termin & Respons & Garansi \\
\hline & MAX & $\mathbf{5}$ & $\mathbf{1 0}$ & $\mathbf{4}$ & $\mathbf{3}$ & $\mathbf{4}$ & $\mathbf{5}$ \\
$\mathbf{1}$ & $761 \mathrm{~A} 0001$ & 2 & 8 & 1 & 2 & 3 & 1 \\
$\mathbf{2}$ & $761 \mathrm{~A} 0002$ & 4 & 9 & 2 & 1 & 2 & 3 \\
$\mathbf{3}$ & $761 \mathrm{~A} 0003$ & 3 & 4 & 3 & 3 & 4 & 2 \\
$\mathbf{4}$ & $761 \mathrm{~B} 0001$ & 4 & 8 & 2 & 1 & 4 & 2 \\
$\mathbf{5}$ & 021A0001 & 2 & 10 & 1 & 3 & 2 & 5 \\
\multicolumn{2}{l}{ TOTAL } & $\mathbf{1 9}$ & $\mathbf{4 9}$ & $\mathbf{1 2}$ & $\mathbf{1 3}$ & $\mathbf{1 9}$ & $\mathbf{1 8}$ \\
\hline
\end{tabular}

Tabel 4. Tabel Data Hasil Perhitungan Matriks Keputusan

\begin{tabular}{cccccccc}
\hline & Criteria & C1 & C2 & C3 & C4 & C5 & C6 \\
\hline & A0 & 0.2105 & 0.2041 & 0.2500 & 0.2308 & 0.2105 & 0.2778 \\
$\mathbf{1}$ & $761 \mathrm{~A} 0001$ & 0.1053 & 0.1633 & 0.0833 & 0.1538 & 0.1579 & 0.0556 \\
$\mathbf{2}$ & $761 \mathrm{~A} 0002$ & 0.2105 & 0.1837 & 0.1667 & 0.0769 & 0.1053 & 0.1667 \\
$\mathbf{3}$ & $761 \mathrm{~A} 0003$ & 0.1579 & 0.0816 & 0.2500 & 0.2308 & 0.2105 & 0.1111 \\
$\mathbf{4}$ & $761 \mathrm{~B} 0001$ & 0.2105 & 0.1633 & 0.1667 & 0.0769 & 0.2105 & 0.1111 \\
$\mathbf{5}$ & $021 \mathrm{~A} 0001$ & 0.1053 & 0.2041 & 0.0833 & 0.2308 & 0.1053 & 0.2778 \\
\hline
\end{tabular}

Berikut rumus perhitungannya:

a. Jika kriteria Benefit maka dilakukan normalisasi mengikuti :

$X_{i j} *=\frac{X_{i j}}{\sum_{i=0}^{m} X_{i j}}$

Di mana :

$X_{i j} *=$ Nilai normalisasi.

b. Jika kriteria Cost maka dilakukan normalisasi mengikuti :

Tahap $1=X_{i j}=\frac{1}{X_{i J}}$
Tahap 2 $=R=\frac{X_{i j}}{\sum_{i=0}^{m} X_{i j}}$

\section{Menghitung Bobot Matriks}

Disinilah hubungan antara metode ROC dan ARAS terjadi, hasil perhitungan matriks keputusan dikali dengan nilai bobot setiap kriteria yang dihitung menggunakan metode ROC.

Tabel 5. Tabel Data Hasil Perhitungan Bobot Matriks

\begin{tabular}{cccccccc}
\hline & Criteria & C1 & C2 & C3 & C4 & C5 & C6 \\
\hline & A0 & 0.0860 & 0.0493 & 0.0396 & 0.0237 & 0.0129 & 0.0077 \\
$\mathbf{1}$ & $\mathbf{7 6 1 A 0 0 0 1}$ & 0.0430 & 0.0395 & 0.0132 & 0.0158 & 0.0096 & 0.0015 \\
$\mathbf{2}$ & $\mathbf{7 6 1 A 0 0 0 2}$ & 0.0860 & 0.0444 & 0.0264 & 0.0079 & 0.0064 & 0.0046 \\
$\mathbf{3}$ & $\mathbf{7 6 1 A 0 0 0 3}$ & 0.0645 & 0.0197 & 0.0396 & 0.0237 & 0.0129 & 0.0031 \\
$\mathbf{4}$ & $\mathbf{7 6 1 B 0 0 0 1}$ & 0.0860 & 0.0395 & 0.0264 & 0.0079 & 0.0129 & 0.0031 \\
$\mathbf{5}$ & $\mathbf{0 2 1 A 0 0 0 1}$ & 0.0430 & 0.0493 & 0.0132 & 0.0237 & 0.0064 & 0.0077 \\
\hline
\end{tabular}

Tabel 6. Tabel Data Hasil Perhitungan Nilai dari Fungsi Optimalisasi

\begin{tabular}{ccccccccc}
\hline & Criteria & C1 & C2 & C3 & C4 & C5 & C6 & S \\
\hline & $\mathbf{A}_{\mathbf{0}}$ & 0.0860 & 0.0493 & 0.0396 & 0.0237 & 0.0129 & 0.0077 & $\mathbf{0 . 2 1 9 2}$ \\
$\mathbf{1}$ & $\mathbf{7 6 1 A 0 0 0 1}$ & 0.0430 & 0.0395 & 0.0132 & 0.0158 & 0.0096 & 0.0015 & $\mathbf{0 . 1 2 2 6}$ \\
$\mathbf{2}$ & $\mathbf{7 6 1 A 0 0 0 2}$ & 0.0860 & 0.0444 & 0.0264 & 0.0079 & 0.0064 & 0.0046 & $\mathbf{0 . 1 7 5 7}$ \\
$\mathbf{3}$ & $\mathbf{7 6 1 A 0 0 0 3}$ & 0.0645 & 0.0197 & 0.0396 & 0.0237 & 0.0129 & 0.0031 & $\mathbf{0 . 1 6 3 5}$ \\
$\mathbf{4}$ & $\mathbf{7 6 1 B 0 0 0 1}$ & 0.0860 & 0.0395 & 0.0264 & 0.0079 & 0.0129 & 0.0031 & $\mathbf{0 . 1 7 5 7}$ \\
$\mathbf{5}$ & $\mathbf{0 2 1 A 0 0 0 1}$ & 0.0430 & 0.0493 & 0.0132 & 0.0237 & 0.0064 & 0.0077 & $\mathbf{0 . 1 4 3 4}$ \\
\hline
\end{tabular}




\section{Menentukan Nilai dari Fungsi Optimalisasi}

Pada tabel 6, tabel data hasil perhitungan dari fungsi optimalisasi yang didapat dari penjumlahan nilai alternatif setiap kriteria, dan hasil tersebut disimbolkan dengan S.

\section{Menentukan Peringkat Tertinggi Dari Alternatif}

Pada tabel 7 adalah hasil peringkat tertinggi didapat dari nilai $\mathrm{S}$ tiap alternatif dibagi dengan nilai S0, dan hasil untuk menentukan peringkat disimbolkan dengan K. Hasil Rekomendasi Supplier yaitu Central Indo Makmur, CV menempati peringkat pertama sebagai supplier yang direkomendasikan dalam memenuhi barang yang dibutuhkan oleh perusahaan dengan melihat semua kriteria sesuai dengan prioritasnya.

Tabel 7. Tabel Data Hasil Peringkat Tertinggi Dari Alternatif.

\begin{tabular}{lccccccccc}
\hline \multicolumn{1}{c}{ Nama Supplier } & C1 & C2 & C3 & C4 & C5 & C6 & S & K & Rank \\
\hline A0 & 0.0860 & 0.0493 & 0.0396 & 0.0237 & 0.0129 & 0.0077 & 0.2192 & 1.0000 & \\
Alva Anugerah, PT & 0.0430 & 0.0395 & 0.0132 & 0.0158 & 0.0096 & 0.0015 & 0.1226 & 0.5596 & $\mathbf{5}$ \\
Aditya Graha, PT & 0.0860 & 0.0444 & 0.0264 & 0.0079 & 0.0064 & 0.0046 & 0.1757 & 0.8017 & $\mathbf{1}$ \\
Abadi Sentosa, PT & 0.0645 & 0.0197 & 0.0396 & 0.0237 & 0.0129 & 0.0031 & 0.1635 & 0.7458 & $\mathbf{3}$ \\
Batang Hari Jaya & 0.0860 & 0.0395 & 0.0264 & 0.0079 & 0.0129 & 0.0031 & 0.1757 & 0.8015 & $\mathbf{2}$ \\
Asia Bearing & 0.0430 & 0.0493 & 0.0132 & 0.0237 & 0.0064 & 0.0077 & 0.1434 & 0.6541 & $\mathbf{4}$ \\
\hline
\end{tabular}

\section{SIMPULAN}

Pemilihan rekomendasi supplier dalam memenuhi kebutuhan perusahaan sudah dapat menggunakan sistem pendukung keputusan berbasis komputer sehingga tidak memakan waktu yang lama dalam proses penilaiannya karena tidak dilakukan secara manual dalam proses penilaiannya dan hasil yang didapat juga maksimal karena dilakukan oleh sistem. Dan penggunaan metode ROC dalam pembobotan kriteria dan ARAS dalam perangkingan dapat membantu perusahaan memperoleh informasi rekomendasi supplier dalam memenuhi kebutuhan perusahaan melalui hasil perangkingan dari supplier yang ada berdasarkan perhitungan menggunakan metode ROC dan ARAS. Di mana nilai ARAS yang didapat berupa nilai $K$ yang di ranking untuk mendapatkan supplier terbaik dalam pemilihan rekomendasi supplier.

\section{REFERENSI}

Ahn, B. S. (2011). Compatible weighting method with rank order centroid: Maximum entropy ordered weighted averaging approach. European Journal of Operational Research, 212(3), 552-559. https://doi.org/10.1016/j.ejor.2011.02.017

Badaruddin, M. (2019). Sistem Pendukung Keputusan Penilaian Kinerja Karyawan Menerapkan Kombinasi Metode Simple Additive Weighting (SAW) dengan Rank Order Centroid (ROC). Jurnal Media Informatika Budidarma, 3(4), 366. https://doi.org/10.30865/mib.v3i4.1508

Fella, F., Susant, W., \& Nora, Y. (2020). Kombinasi Metode Pendukung Keputusan untuk Seleksi Penerima Beras Miskin ( Raskin ). Aplikasi Teknologi Komputer Dan Informasi, 2(1), 45-49.

Handayani, L., Syahrizal, M., \& Tampubolon, K. (2019). Pemilihan Kepling Teladan Menerapkan Metode Rank Order Centroid (Roc) Dan Metode Additive Ratio Assessment (Aras) Di Kecamatan Medan Area. KOMIK (Konferensi Nasional Teknologi Informasi Dan Komputer), 3(1), 532-538. https://doi.org/10.30865/komik.v3i1.1638

Kwok, E., \& Susanti, W. (2019). Penerapan Metode Regresi Linier dalam Aplikasi Sistem Peramalan Jumlah Bahan Baku untuk Produksi Tahu. 1(2), 121-128.

Laila, F., \& RMS, A. S. (2019). Penentuan Supplier Bahan Baku Restaurant XO Suki Menggunakan Metode Weighted Product. Jurnal Teknologi Dan Ilmu Komputer Prima 
(JUTIKOMP), 2(1), 1-4. https://doi.org/10.34012/jutikomp.v2i1.412

Lubis, A. I., Sihombing, P., \& Nababan, E. B. (2020). Comparison SAW and MOORA Methods with Attribute Weighting Using Rank Order Centroid in Decision Making. MECnIT 2020 - International Conference on Mechanical, Electronics, Computer, and Industrial Technology, 127-131. https://doi.org/10.1109/MECnIT48290.2020.9166640

Majdi, A. H. (2017). Penerapan Metode Promethee dengan Entropy Dalam Pengambilan Keputusan untuk Menentukan Siswa Berprestasi. Edumatic: Jurnal Pendidikan Informatika, 1(2), 55-64.

Mesran, M. (2018). Sistem Pendukung Keputusan Pemilihan Supplier Barang Lemari Menerapkan Metode MOORA. (338). https://doi.org/10.31219/osf.io/brgjs

Mesran, M., Afriany, J., \& Sahir, S. H. (2019). Efektifitas Penilaian Kinerja Karyawan Dalam Peningkatan Motivasi Kerja Menerapkan Metode Rank Order Centroid (ROC) dan Additive Ratio Assessment (ARAS). Prosiding Seminar Nasional Riset Information Science (SENARIS), 1, 813-821. https://doi.org/10.30645/senaris.v1i0.88

Muntohar, A. (2020). Sistem Informasi Data Klien Berbasis Java Pada Kantor Notaris dan PPAT Arif. Edumatic: Jurnal Pendidikan Informatika, 4(2), 58-67. https://doi.org/10.29408/edumatic.v4i2.2515

Ndruru, R. K. (2020). Penerapan Metode Additive Ratio Assessment (ARAS) dan Rank Order Centroid (ROC) Dalam Pemilihan Jaksa Terbaik Pada Kejaksaan Negeri Medan. Seminar Nasional Teknologi Komputer \& Sains (SAINTEKS), 1(1), 367-372.

Pratiwi, F., Tinus Waruwu, F., Putro Utomo, D., \& Syahputra, R. (2019). Penerapan Metode Aras Dalam Pemilihan Asisten Perkebunan Terbaik Pada PTPN V. Seminar Nasional Teknologi Komputer \& Sains (SAINTEKS), 651-662. Medan: STMIK Budi Darma.

Rizki, R., \& Mulyati, S. (2020). Implementasi One Time Password Menggunakan Algoritma SHA-512 Pada Aplikasi Penagihan Hutang PT. XHT. Edumatic: Jurnal Pendidikan Informatika, 4(1), 111-120.

Sakti, R. H., Sukardi, S., Giatman, M., Nazar, E., Wakhinuddin, W., \& Waskito, W. (2020). Flipped Classroom-Computer Based Instruction untuk Pembelajaran Pada Revolusi Industri 4.0: Rancang Bangun dan Analisis Kebutuhan. Edumatic: Jurnal Pendidikan Informatika, 4(1), 63-72.

Supriyanto, Mesran, Kusnady, D., Weny, \& Murtopo. (2019). Implementation of ComputerBased Systems in Efficient Credit Acceptance Decisions Applying the Additive Ratio Assessment (ARAS) Method. Journal of Physics: Conference Series, 1424(1). https://doi.org/10.1088/1742-6596/1424/1/012018

Trimulia, C., Defit, S., \& Nurcahyo, G. W. (2018). Pemilihan Supplier Obat yang tepat dengan Metode Simple Additive Weighting. Jurnal Sains Dan Teknologi Industri, 16(1), 37-42. https://doi.org/10.24014/sitekin.v16i1.6735

Wardani, S., Parlina, I., \& Revi, A. (2018). Analisis Perhitungan Metode Moora Dalam Pemilihan Supplier Bahan Bangunan Di Toko Megah Gracindo Jaya. Jurnal Nasional Informatika Dan Teknologi Jaringan, 3(1), 95-99.

Zavadskas, E. K., \& Turskis, Z. (2010). A new additive ratio assessment (ARAS) method in multicriteria decision-making. Technological and Economic Development of Economy, 16(2), 159-172. https://doi.org/10.3846/tede.2010.10 